\title{
Accurate Method of HPLC-Ms/Ms Determination of Mycophenolic Acid in Human Plasma
}

\author{
Khokhlov AL ${ }^{1,2}$, Yaichkov II ${ }^{1,2 *}$, Shitov LN1,2, Dzhurko YA², Shitova AM ${ }^{2,4}$, Ryska M $^{3}$, Kubeš V³, Shabrov VN² and Miroshnikov AE1 \\ ${ }^{1}$ State Budget-funded Educational Establishment of Higher Professional Education, Yaroslavl State Medical University of the Ministry of Health of the Russian Federation, \\ Yaroslavl, Russia \\ ${ }^{2}$ Quinta-Analytica Yaroslavi LLC, Yaroslavl, Russia \\ ${ }^{3}$ Quinta-Analytica s.r.o., Prague, Czech Republic \\ ${ }^{4}$ State Educational Establishment of Higher Professional Education "Yaroslavl State University named after P. G. Demidov" of the Ministry of Education and Science of \\ the Russian Federation, Yaroslavl, Russia
}

\begin{abstract}
A simple, accurate and precise method was developed using HPLC-MS/MS to quantify mycophenolic acid in human plasma. Mycophenolic acid-D3 was used as internal standard. Sample preparation involved protein precipitation. Chromatographic analysis was performed on a Phenomenex Kinetex C18 $(30 \mathrm{~mm} \times 4.6 \mathrm{~mm}, 2.6 \mu \mathrm{m})$ column using acetonitrile-water as the mobile phase. Detection in negative ionization mode was used to quantify mycophenolic acid by multiple reaction monitoring. The calibration curve was linear in the range of $0.5-30 \mu \mathrm{g} / \mathrm{mL}$, with intra-and inter-batch values for accuracy and precision (coefficient of variation) ranging from 99.76 to $111.38 \%$ and from 2.54 to $9.01 \%$, respectively. The method was successfully applied to conduct a pharmacokinetic study of $360 \mathrm{mg}$ coated tablet "Myfortic" in 48 healthy participants; 768 blood samples were analysed.
\end{abstract}

Keywords: Mycophenolic acid; HPLC-MS/MS; Plasma; Myfortic

\section{Introduction}

Mycophenolate sodium is an immunosuppressive drug which effect is based on selective, reversible and competitive inhibition of the enzyme inosine monophosphate dehydrogenase which is necessary for the synthesis of guanosine, and its incorporation into the DNA molecule. This results in inhibition of growth and division of lymphocytes, induces their apoptosis, which leads to a decrease of immunity [1].

Mycophenolic acid is primarily metabolized by glucuronyl transferase with the formation of the main pharmacologically inactive metabolite-phenolic glucuronide of mycophenolic acid. About $28 \%$ of the oral dosage of the drug is exposed to the first-pass degradation in patients with a stable functioning kidney transplant, receiving the base immunosuppressive therapy with cyclosporine in the form of a microemulsion.

Mycophenolate sodium is highly variable drug. It is associated with enterohepatic recirculation: glucuronide of mycophenolic acid is secreted with bile into the intestine and is destroyed by deconjugation by gut organisms. Therefore, in 6-8 $\mathrm{h}$ after administration the drug noted a second peak of concentration, which corresponds to the reabsorption of deconjugating mycophenolic acid. Bioavailability of the coated tablets is $72 \%$, the absorption rate is $93 \%$, time-to-peak concentration is $1.5-2 \mathrm{~h}$, elimination half-time is $11.7 \mathrm{~h}$, volume of distribution is $50 \mathrm{~L}$. Mycophenolic acid and the glucuronide are highly protein-binding: $97 \%$ and $82 \%$, respectively [2]. This drug in combination with cyclosporine and corticosteroids is used in kidney transplantation to prevent rejection [3].

The above features of mycophenolate sodium biopharmaceutical properties make high demands to methodology of pharmacokinetic and bioequivalence studies of drugs containing this substance [4]. Also for the right selection of a dosage it is necessary to control concentration of mycophenolic acid in plasma. The phenyl glucuronide of the drug has the ability of back-conversion after blood sampling collection. It can lead to exaggerated measurements and consequently overstated results of bioanalytical studies.
HPLC-MS/MS is generally used for bioassay [5-7]. There are a lot of methods of determination of mycophenolic acid in human plasma using deproteinization [8-13] and solid-phased extraction [14]. But back-conversion of phenyl glucuronide of mycophenolic acid in plasma storage process has not been investigated. Therefore, development of a new fast and accurate method for measurement of mycophenolic acid plasma concentrations is necessary.

\section{Subjects and Methods}

HPLC-MS/MS system for measurement of mycophenolic acid concentrations includes two pumps Flux Instruments 2200 Rheos, autosampler CTC Analytics PAL HTS and triple quadrupole mass spectrometer "Thermo Scientific TSQ Quantum Discovery Max" equipped with HESI ion source.

Reference standard of mycophenolate sodium was produced by Emcure Pharmaceuticals Limited (India), mycophenolic acid-D3 (MPA-D3) and phenyl glucuronide of mycophenolic acid (MPAG) were procured by TLC Pharmachem (Canada) (Figure 1). HPLC grade acetonitrile was obtained from Merck (Darmstadt, Germany). Water was prepared with the help of Direct Q3 UV water purification system (Figure 1).

The standard stock solutions of MPA, MPAG and MPA-D3 were prepared by dissolving accurately weighed substances in acetonitrile.

\footnotetext{
*Corresponding author: Yaichkov II, State Budget-funded Educational Establishment of Higher Professional Education, Yaroslavl State Medical University of the Ministry of Health of the Russian Federation, Yaroslavl, Russia, Tel: 375-296053960; E-mail: ilya_1993_08@mail.ru

Received November 17, 2016; Accepted December 12, 2016; Published December 23, 2016

Citation: Khokhlov AL, Yaichkov II, Shitov LN, Dzhurko YA, Shitova AM, et al (2016) Accurate Method of HPLC-Ms/Ms Determination of Mycophenolic Acid in Human Plasma. J Bioequiv Availab 9: 306-311. doi: 10.4172/jbb.1000316

Copyright: (c) 2016 Khokhlov AL, et al. This is an open-access article distributed under the terms of the Creative Commons Attribution License, which permits unrestricted use, distribution, and reproduction in any medium, provided the original author and source are credited.
} 


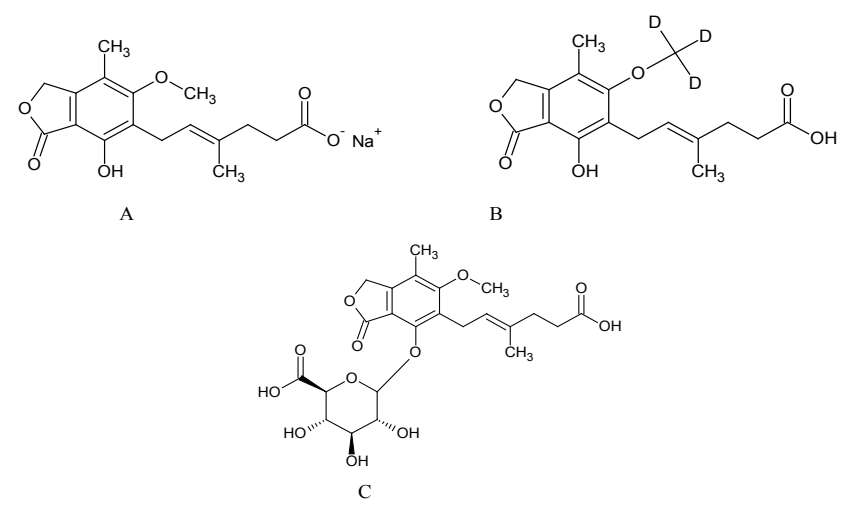

Figure 1: Structures of mycophenolate sodium (A), mycophenolic acid-D3, (B) and phenyl glucuronide of mycophenolic acid (C).

Working solutions were prepared by appropriate dilution of stock solutions in acetonitrile. Calibration standards and quality control samples were prepared by adding $50 \mu \mathrm{L}$ of the working solution to $950 \mu \mathrm{L}$ of blank plasma. There are eight calibration concentrations: $0.5,1.0,4.0,8.0,12.0,18.0,24.0,30.0 \mu \mathrm{g} / \mathrm{mL}$, and six quality control samples: $0.5,1.5 \mu \mathrm{g} / \mathrm{mL}$ (LQC, low quality control), $5.0,15.0 \mu \mathrm{g} / \mathrm{mL}$ (MQC, medium quality control), $22.5,30.0 \mu \mathrm{g} / \mathrm{mL}$ (HQC, high quality control).

The test product was Myfortic $360 \mathrm{mg}$ coated tablet from Novartis Pharma Stein AG, Switzerland (batch number: S0347, expiry date: 12.2014)

\section{Analysis of plasma samples}

The plasma samples $(50 \mu \mathrm{L})$ were deproteinized with internal standard solution $(1.5 \mu \mathrm{g} / \mathrm{mL})$ in acetonitrile $(450 \mu \mathrm{L})$ and $5 \mu \mathrm{L}$ portions of supernatant obtained after centrifugation at a speed of 2500 $\mathrm{rpm}$. were directly injected into the chromatographic system.

The chromatographic separation was achieved by using Phenomenex Kinetex C18 (30 mm $\times 4.6 \mathrm{~mm}, 2.6 \mu \mathrm{m})$ analytical column and Phenomenex Security guard C18 $(4 \mathrm{~mm} \times 3 \mathrm{~mm})$ pre-column with gradient elution of the mobile phase composed of acetonitrile and water (Table 1) at a flow rate $0.4 \mathrm{~mL} / \mathrm{min}$ and a room temperature.

Detection was performed (Table 2) in negative ion mode, using the Heated-ESI ion source. An MRM transition of $319 \rightarrow 191+205 \mathrm{~m} / \mathrm{z}$ was selected for the analyte, and $322 \rightarrow 191+205 \mathrm{~m} / \mathrm{z}$ for the internal standard.

\section{Results}

\section{Method validation procedures}

Validation was conducted in accordance with requirements of FDA [15] and EMEA guidelines [16] on the following parameters: selectivity, linearity, lower Limit of Quantification, accuracy and precision, matrix effect, recovery, carryover effect, dilution integrity and stability.

The chromatograms obtained with blank plasma (6 samples from independent sources, including haemolyzed and hyperlipidaemic plasma) did not have any interference at the retention time of the analyte and the internal standard (Figure 2). Therefore, the developed method is selective.

The linearity of analytical procedure was evaluated in the concentration range from $0.5-30.0 \mu \mathrm{g} / \mathrm{mL}$ by measuring area ratio response ("analyte/internal standard"). The correlation coefficient was ranged from 0.9985 to 0.9996 . The lower limit of quantification (LLOQ) was $0.5 \mu \mathrm{g} / \mathrm{mL}$.

Accuracy and precision were determined by analysing of six replicates of QC samples. The results are represented in Table 3 and Figure 3. Diluting plasma sample to half did not affect the accuracy and precision.

The MDA recovery rate was $84.18 \%$ and $90.33 \%$ at low and high concentration levels, respectively. Matrix effect was assessed by comparing the mean area ratio of plasma sample with mean area ratio of acetonitrile solutions of MDA and MDA-D3. The Normalized Matrix Factor (NMF) values were 0.892 and 0.877 at low and high concentration levels, respectively; the Coefficients of Variation (CV) for NMF were $11.94 \%$ and $1.92 \%$, respectively.

The stability study was carried out at concentrations of $1.50 \mu \mathrm{g} /$ $\mathrm{mL}$ and $22.50 \mu \mathrm{g} / \mathrm{mL}$ with six replicates of each level. Short-term, long-term, freeze and thaw stability was demonstrated. The results are represented in Table 4.

There was no significant carry-over after three high concentration injections: Chromatograms obtained with blank plasma did not have peaks at the retention time of the analyte and the internal standard.

Back-conversion of MPAG was evaluated after addition $50 \mu \mathrm{L}$ of MPAG acetonitrile solution to $950 \mu \mathrm{L}$ blank plasma. The concentration of MPAG at plasma samples was $100 \mu \mathrm{g} / \mathrm{mL}$, which corresponds to a maximum expected concentration of this metabolite in the samples of volunteers. The comparing of concentration of MPA was carried out after preparation of MPAG samples and after $24 \mathrm{~h}$ of storage of MPAG samples. There was no significant back-conversion MPAG: concentration of MPA was $2.58 \%$ from LLOQ.

The results of all validation tests were acceptable.

\section{The pharmacokinetic study}

The investigation was conducted in accordance with requirements of the National Standard of the Russian Federation GOST R 523792005 "Good Clinical Practice requirements" [17], guidances of FDA [18] and EMEA [19] as well as in accordance with ethical principles of the Declaration of Helsinki [20].

\begin{tabular}{|c|c|c|}
\hline Time (min) & Acetonitrile (\% v/v) & Water (\% v/v) \\
\hline $0-1.0$ & 40 & 60 \\
\hline $1.0-1.5$ & 65 & 35 \\
\hline $1.5-2.0$ & 90 & 10 \\
\hline $2.0-2.5$ & 90 & 10 \\
\hline $2.5-3.0$ & 65 & 35 \\
\hline $3.0-3.5$ & 40 & 60 \\
\hline $3.5-4.5$ & 40 & 60 \\
\hline
\end{tabular}

Table 1: Parameters of gradient elution.

\begin{tabular}{|c|c|}
\hline Parameter & Value \\
\hline Spray voltage & $3250 \mathrm{~V}$ \\
\hline Capillary temperature & $222^{\circ} \mathrm{C}$ \\
\hline Sheath gas & 30 arb. unit \\
\hline Sweep gas & 2 arb. unit \\
\hline Aux gas & 20 arb. unit \\
\hline Vaporizing temperature & $324^{\circ} \mathrm{C}$ \\
\hline Collision gas pressure & $1.5 \mathrm{mTorr}$ \\
\hline
\end{tabular}

Table 2: Parameters of mass spectrometry detection. 


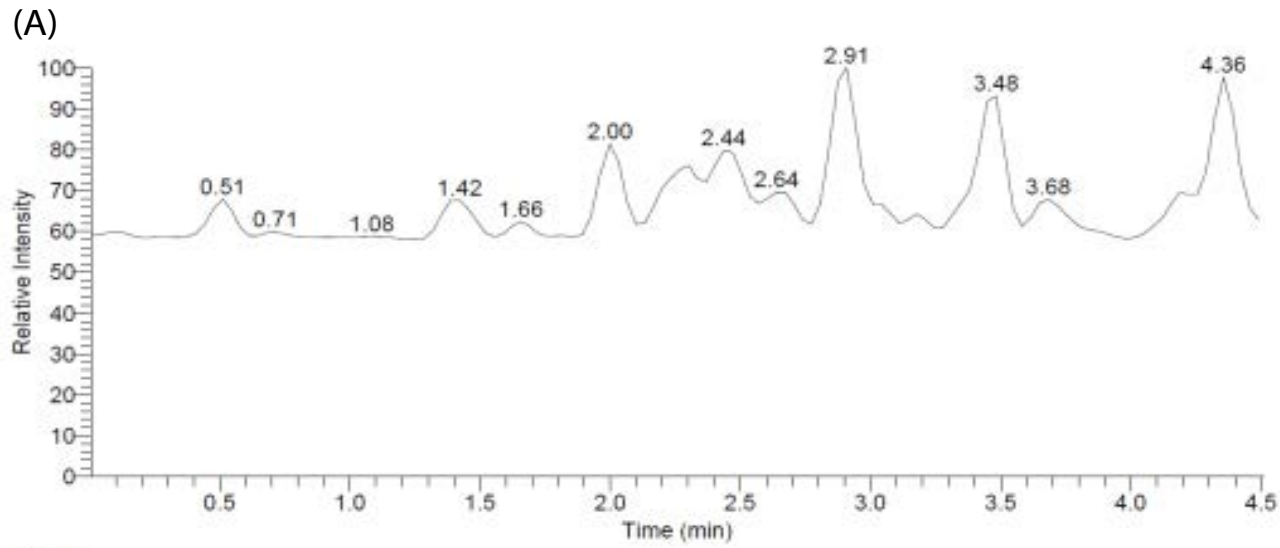

dMPA

V13 PB 02 - TIC RT: $0.01-4.51$ NL: $2.03 E 1$

F: - c ESI SRM ms2 322.10 [191.00-191.10, 205.05-205.15]

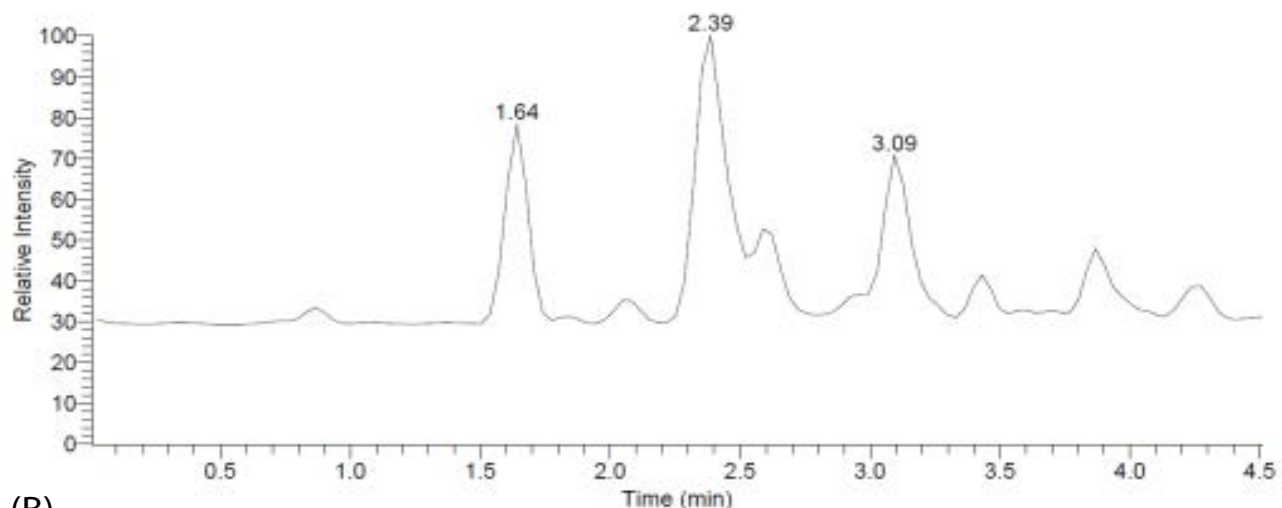

(B)
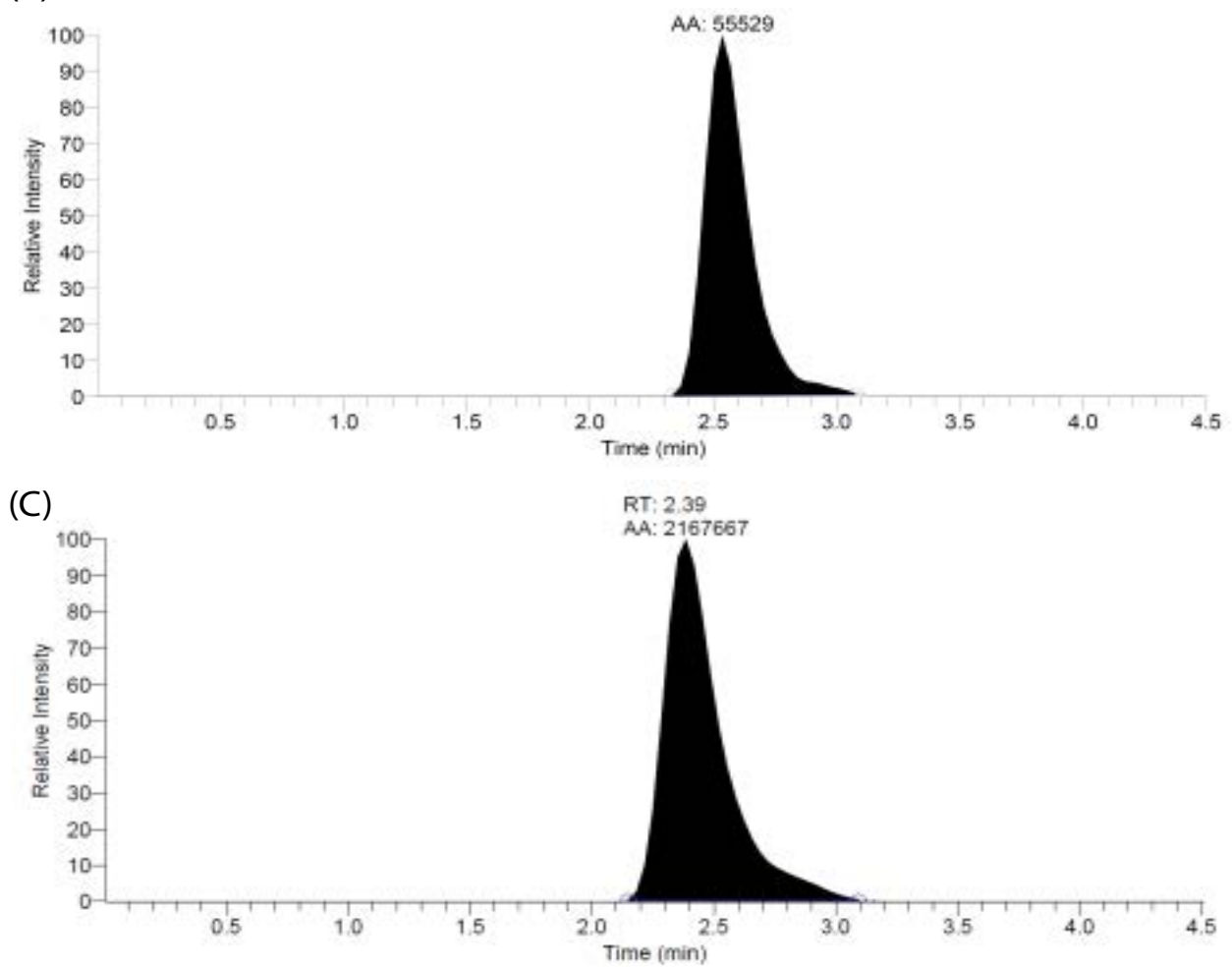

Figure 2: (A) The chromatograms of blank plasma. (B) Plasma with analyte. (C) Internal standard. 
Citation: Khokhlov AL, Yaichkov II, Shitov LN, Dzhurko YA, Shitova AM, et al. (2016) Accurate Method of HPLC-Ms/Ms Determination of Mycophenolic Acid in Human Plasma. J Bioequiv Availab 9: 306-311. doi: 10.4172/jbb.1000316

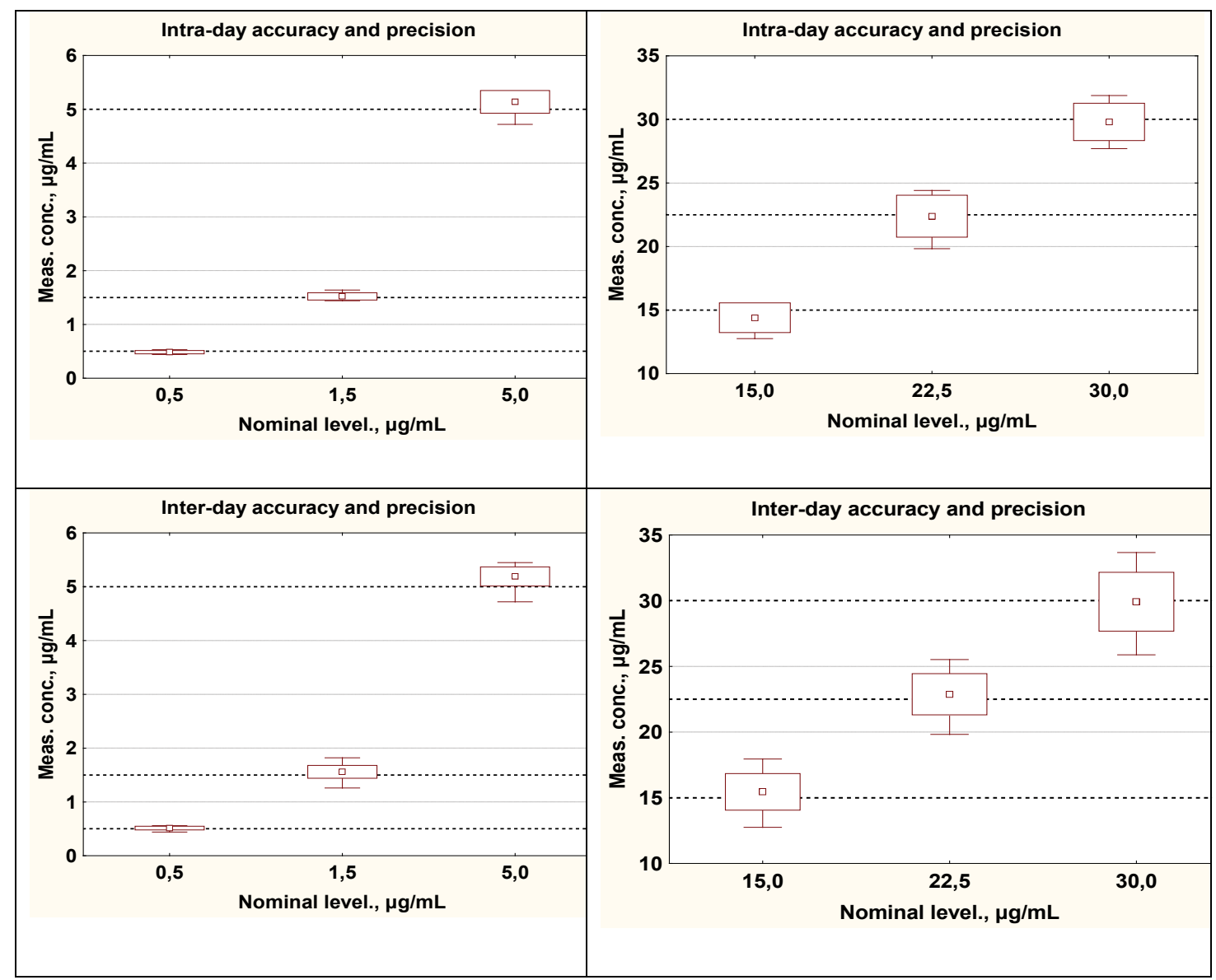

Figure 3: Intra- and inter-day accuracy and precision.

\begin{tabular}{|c|c|c|c|c|c|c|}
\hline $\begin{array}{l}\text { Concentration } \\
(\mu \mathrm{g} / \mathrm{mL})\end{array}$ & 0.50 & 1.50 & 5.00 & 15.00 & 22.50 & 30.00 \\
\hline \multicolumn{7}{|c|}{ Intra-day accuracy and precision } \\
\hline Mean $(n=6)$ & 0.54 & 1.67 & 5.33 & 16.93 & 24.29 & 31.91 \\
\hline SD & 0.02 & 0.08 & 0.14 & 0.74 & 0.97 & 1.44 \\
\hline Precision (CV) \% & 4.42 & 4.62 & 2.54 & 4.36 & 4.01 & 4.52 \\
\hline Accuracy, \% & 108.62 & 111.38 & 106.67 & 112.85 & 107.96 & 106.37 \\
\hline \multicolumn{7}{|c|}{ Inter-day accuracy and precision } \\
\hline Mean $(n=18)$ & 0.51 & 1.56 & 5.19 & 15.45 & 22.88 & 29.93 \\
\hline SD & 0.03 & 0.12 & 0.18 & 1.39 & 1.57 & 2.24 \\
\hline Precision (CV)\% & 6.75 & 7.63 & 3.42 & 9.01 & 6.87 & 7.48 \\
\hline Accuracy, \% & 102.78 & 104.04 & 103.83 & 103.03 & 101.70 & 99.76 \\
\hline
\end{tabular}

Table 3: Accuracy and precision for MDA QC samples.

\begin{tabular}{|c|c|c|c|c|}
\hline & \multirow{2}{*}{ Short-term stability (24 h) } & \multicolumn{2}{|c|}{ Long-term stability } & \multirow{2}{*}{ Freeze and thaw stability } \\
\hline & & 37 days & 119 days & \\
\hline \multicolumn{5}{|c|}{$1.50 \mu \mathrm{g} / \mathrm{mL}$} \\
\hline Mean & 1.49 & 1.51 & 1.55 & 1.58 \\
\hline Precision, \% & 4.04 & 5.72 & 4.23 & 5.47 \\
\hline Accuracy, \% & 99.18 & 100.38 & 103.24 & 105.10 \\
\hline \multicolumn{5}{|c|}{$22.50 \mu \mathrm{g} / \mathrm{ml}$} \\
\hline Mean & 22.38 & 21.33 & 22.69 & 23.30 \\
\hline Precision, \% & 4.51 & 2.44 & 2.82 & 3.72 \\
\hline Accuracy, \% & 99.46 & 94.79 & 100.86 & 103.55 \\
\hline
\end{tabular}

Table 4: Stability study of MDA at plasma. 
Citation: Khokhlov AL, Yaichkov II, Shitov LN, Dzhurko YA, Shitova AM, et al. (2016) Accurate Method of HPLC-Ms/Ms Determination of Mycophenolic Acid in Human Plasma. J Bioequiv Availab 9: 306-311. doi: 10.4172/jbb.1000316

The study was conducted on 48 healthy participants aged from 18 to 45 years that met the inclusion criteria: verified diagnosis "healthy", body mass index in the range of $18.5 \mathrm{~kg} / \mathrm{m}^{2}$ to $24.9 \mathrm{~kg} /$ $\mathrm{m}^{2}$, body weight more than $45 \mathrm{~kg}$; ability to follow the requirements of the study protocol, lack of allergy, normalities revealed by clinical instrumental and laboratory investigations at screening, lack of hypersensitivity to mycophenolate sodium, mycophenolate mofetil or to any other substance included in the formulation of the drug, lack of cardiovascular, bronchopulmonary, neuroendocrine, immune, gastrointestinal, liver, kidney, or blood diseases; lack of acute infectious disease within the 4 weeks preceding the investigation; lack of intake of any medicinal products within 2 weeks of the start of the study, lack of excessive alcohol consumption.

All participants were tested for use of drugs and alcohol. Women additionally performed a pregnancy test. Blood samples for subsequent quantitative determination of mycophenolic acid were collected into a pre-labelled vacuum centrifuge tubes containing EDTA as an anticoagulant prior to administrating the drug, $15 \mathrm{~min}, 30 \mathrm{~min}, 45$ min, 1 h, 1.5 h, 2 h, 3 h, 4 h, 6 h, 8 h, 12 h, 18 h, 24 h, 48 h, 72 h after administration of a tablet of "Myfortic" at a dose of $360 \mathrm{mg}$ [4]. After the blood sampling procedure, tubes were centrifuged at $2500 \mathrm{rpm}$ for $10 \mathrm{~min}$. The resulting plasma was immediately frozen at $-20^{\circ} \mathrm{C}$ until it was assayed. There were taken and analysed 768 blood samples.

Pharmacokinetic parameters such as maximum measured plasma concentration $\left(\mathrm{C}_{\max }\right)$, area under the pharmacokinetic "concentrationtime" curve from zero to the last blood sampling procedure $\left(\mathrm{AUC}_{0-\mathrm{t}}\right)$, relative absorption rate $\left(\mathrm{C}_{\max } / \mathrm{AUC}_{0-\mathrm{t}}\right)$, time-to-peak concentration $\left(\mathrm{T}_{\max }\right)$ were calculated. Statistical analyses performed with the $\mathrm{Rv}$ application packages 3.2.1, Module Bear (Lee, Hsinya and Lee, Yungjin (2014), bear: Data Analysis Tool for Average Bioequivalence and Bioavailability, Rpackage version 2.6.4) and StatSoft Statistica v.12. The results are represented in Table 5 and Figure 4.

\section{Conclusion}

The new accurate, selective, fast method was developed for determining concentration of mycophenolic acid in blood plasma by

\begin{tabular}{|c|c|c|c|c|}
\hline Parameters & $\begin{array}{l}C_{\max } \\
\mu \mathrm{g} / \mathrm{ml}\end{array}$ & $\mathbf{T}_{\mathbf{m} \text { max }}$ & $\begin{array}{l}\mathrm{AUC}_{0 . \mathrm{t}} \\
\mu \mathrm{g} \cdot \mathrm{h} / \mathrm{ml}\end{array}$ & $\mathbf{C}_{\max }{ }_{\mathbf{h}^{-1}}{ }^{-1} C_{0-t^{\prime}}$ \\
\hline$M \pm S D$ & $12.29 \pm 5.53$ & $2.9 \pm 2.4$ & $22.90 \pm 11.11$ & $0.5591 \pm 0.1812$ \\
\hline Min & 1.15 & 1.0 & 6.90 & 0.1667 \\
\hline Max & 23.34 & 18.0 & 57.32 & 0.9939 \\
\hline
\end{tabular}

Table 5: Pharmacokinetic parameters of coated tablet "Myfortic" $360 \mathrm{mg}$.

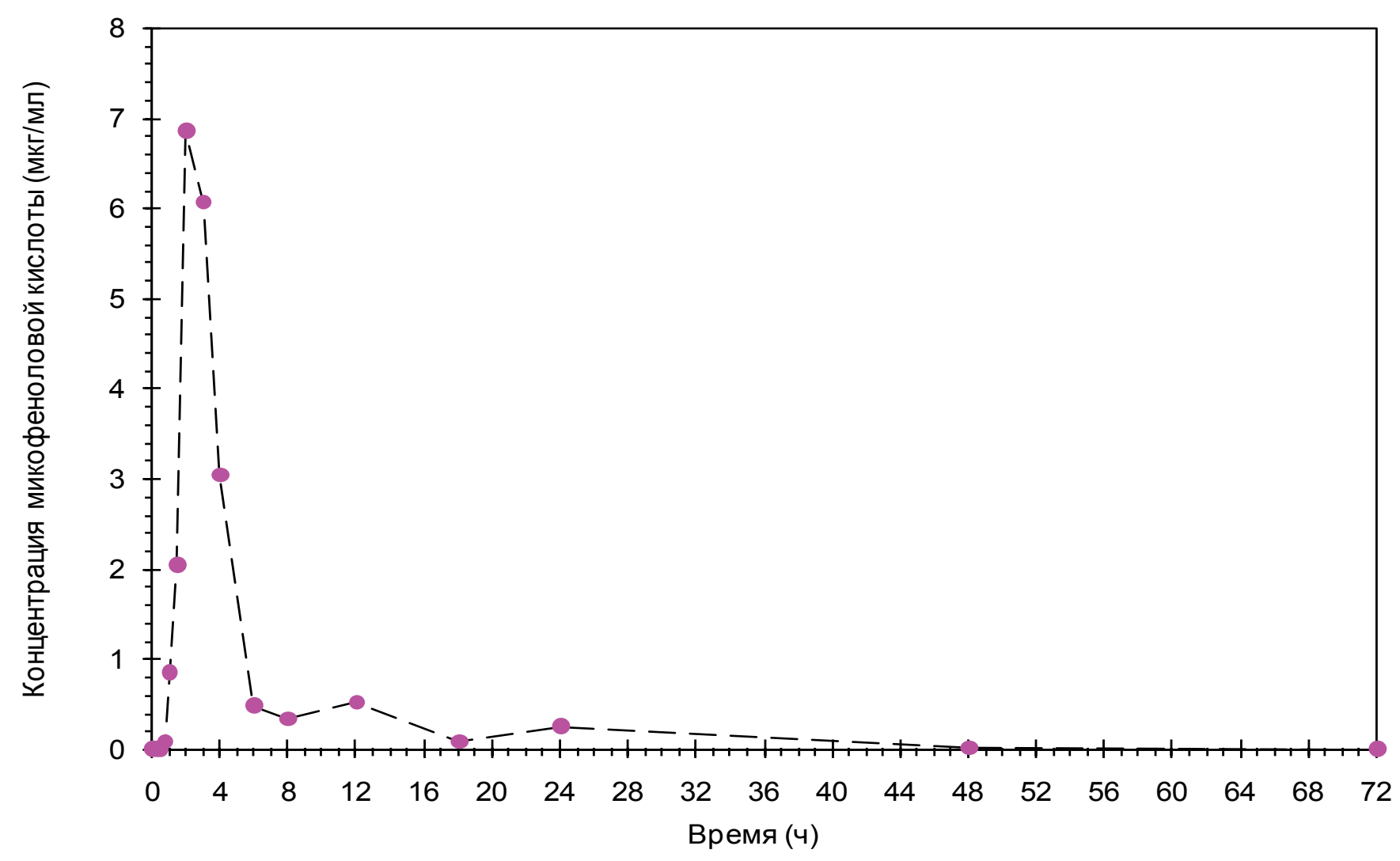

Figure 4: Averaged pharmacokinetic profiles of plasma mycophenolic acid concentrations after a single dose of "Myfortic". 
Citation: Khokhlov AL, Yaichkov II, Shitov LN, Dzhurko YA, Shitova AM, et al. (2016) Accurate Method of HPLC-Ms/Ms Determination of Mycophenolic Acid in Human Plasma. J Bioequiv Availab 9: 306-311. doi: 10.4172/jbb.1000316

using HPLC-MS/MS. Validation was conducted in accordance with requirements of FDA and EMEA guidelines. Back-conversion of MPAG was studied. This procedure has been used to investigation the pharmacokinetics of coated tablets of mycophenolate sodium.

\section{References}

1. Budde K, Glander P (2008) Pharmacokinetic principles of immunosuppressive drugs. Ann Transp 13: 5-10.

2. Salvadori M, Holzer H, Mattos A, Solinger H, Arns W, et al. (2003) Entericcoated mycophenolate sodium is therapeutically equivalent to micophenolate mofetil in de novo renal transplant recipients. Am J Transp 4: 231-236.

3. Karam G, Kalble T, Alcaraz A, Aki FT, Budde K, et al. (2013) Guidelines on renal transplantation. Eur Assoc Urol.

4. Khokhlov AL, Lileeva EG, Sinitsina OA, Speshilova SA, Demarina SM, et al. (2014) The problems of undertaking bioanalytical part of bioequivalence studies of medicines in Russia. Pharmacokin Pharmacodyn 1: 37-43.

5. Guan L, Li H, Chen Z, Frick G, Nichols A (2016) An Assessment of the Pharmacokinetics and Tolerability of Single-Ascending Doses of Desvenlafaxine Administered to Healthy Chinese Subjects. J Bioequiv Bioavailab 8: 99-105.

6. Khokhlov AL, Shitov LN, Ryska M, Dzhurko YA, Kubes V, et al. (2016) The Pharmacokinetic Properties and Bioequivalence of Methyldopa Formulations: Results of an Open-label, Randomized, Two-period, Crossover, Single-dose Study. J Bioequiv Bioavailab 8: 185-190.

7. Vargas M, Villarraga EA (2016) Bioequivalence Study of Two Formulations Containing Lurasidone $80 \mathrm{mg}$ Tablets in Healthy Colombian Volunteers. J Bioequiv Bioavailab 8: 220-223.

8. Benech H, Hascoet S, Furlan V, Durrbach A (2007) Development and validation of an LC/MS/MS assay for mycophenolic acid in human peripheral blood mononuclear cells. J Chrom B 853: 168-174.

9. Brandhorst G, Streit F, Goetze S, Oellerich M, Armstrong VW (2006) Quantification by Liquid Chromatography Tandem Mass Spectrometry of Mycophenolic Acid and Its Phenol and Acyl Glucuronide Metabolites. Clin Chem 52: 1962-1964.
10. Decavele ASC, Favoreel N, Heyden FV, Verstraete AG (2011) Performance of the Roche Total Mycophenolic Acid assay on the Cobas Integra 400, Cobas 6000 and comparison to LC-MS/MS in liver transplant patients. Clin Chem Lab Med 49: 1159-1165.

11. Fleischmann T, Merdink J, Faulconbridge S, Clarke T (2007) LC/MSMS Methods for Quantitative Determination of Mycophenolic Acid in Human Plasma. Curr Sep Drug Devel 22: 27-29.

12. Klepacki J, Klawitter J, Bendrick-Peart J, Schniedewind B, Heischmann S, et al. (2012) A high-throughput U-HPLC-MS/MS assay for the quantification of mycophenolic acid and its major metabolites mycophenolic acid glucuronide and mycophenolic acid acyl-glucuronide in human plasma and urine. J Chrom B 884: 113-119.

13. Upadhyay V, Trivedi V, Shah G, Yadav M, Shrivastav PS (2013) Determination of mycophenolic acid in human plasma by ultra-performance liquid chromatography tandem mass spectrometry. J Pharm Anal 4: 205-216.

14. Annesley TM, Clayton LT (2005) Quantification of Mycophenolic Acid and Glucuronide Metabolite in Human Serum by HPLC-Tandem Mass Spectrometry. Clin Chem 51: 872-877.

15. Food and Drugs Administration (2013) Guidance for Industry: Bioanalytical method validation. Department of Health and Human Services, USA.

16. European Medicines Agency (EMEA) (2009) Guidance on Validation of Bioanalytical Methods. London, UK.

17. Federal Agency on Technical Regulating and Metrology (2005) Good Clinical Practice requirements. National Standard of the Russian Federation, Moscow, Russia.

18. Food and Drugs Administration (2010) Guidance for Industry: Waiver of In vivo Bioavailability and Bioequivalence Studies for Immediate Release Solid Oral Dosage Forms Based on Biopharmaceutics Classification System. U.S. Department of Health and Human Services.

19. European Medicines Agency (EMEA) (2010) Guidance on the investigation of bioequivalence, London, UK.

20. World Medical Assembly (2013) Declaration of Helsinki of the AMM-Ethical Principles for Medical Research in humans, $64^{\text {th }}$ General Assembly, Fortaleza, Brazil. 